\title{
Identification of phytotoxins from Botryosphaeria obtusa, a pathogen of black dead arm disease of grapevine
}

\author{
Jules Désiré Djoukeng • Suzanna Polli • \\ Philippe Larignon • Eliane Abou-Mansour
}

Received: 14 June 2008 / Accepted: 8 December 2008 / Published online: 16 January 2009

(C) KNPV 2009

\begin{abstract}
A bioassay-guided fractionation of a culture filtrate of Botryosphaeria obtusa led to the isolation of four dihydroisocoumarins, named mellein 1, 4-hydroxymellein 2, 7-hydroxymellein 3 and the new 4,7-dihydroxymellein 4. LC-UV-DAD-MS analysis of vine wood infected by $B$. obtusa revealed the presence of mellein (1). Botryosphaeria obtusa was also able to oxidise wood $\delta$-resveratrol into the dimer delta-viniferin. The structures of isolated phytotoxins were established on the basis of IR, MS, 1D and 2D NMR.
\end{abstract}

J. D. Djoukeng $\cdot$ S. Polli $\cdot$ E. Abou-Mansour Institute of Biology, University of Neuchâtel, rue Emile Argand 11, 2009 Neuchâtel, Switzerland

P. Larignon

Institut Français de la Vigne et du Vin,

Unité Rhône-Méditerranée, Domaine de Donadille,

30230 Rodilhan, France

E. Abou-Mansour $(\bowtie)$

Plant Biology Department, University of Fribourg,

3 , rue Gockel,

1700 Fribourg, Switzerland

e-mail: eliane.abou-mansour@unifr.ch
Keywords Black dead arm - Botryosphaeria obtusa . Grapevine disease $\cdot$ Isocoumarins $\cdot$ Melleins ·

Phytotoxins

\section{Introduction}

Botryosphaeria obtusa is a fungal pathogen associated with black dead arm (BDA) on vine. BDA was identified for the first time in Hungary (Lehoczky 1974) and later in Italy (Cristinzio 1978; Rovesti and Montermini 1987). It attacks the wood of the plant causing decline and eventually death. This disease is easily confused with esca disease because of the similarity of foliar symptoms. Like esca and eutypa dieback, it affects vines more than eight years-old (Larignon et al. 2001). Symptom differentiation between esca and BDA diseases has been extensively reported by Larignon and Dubos (2001). Previous chemical investigation of $B$. obtusa, which also causes black rot of apple fruit, reported the isolation of five phenolic dihydroisocoumarins (mellein, cis$(3 R, 4 R), 4$-hydroxymellein and 5-hydroxymellein) (Venkatasubbaiah and Chilton 1990). In the present work, we report the identification by $\mathrm{LC}^{-\mathrm{MS}^{\mathrm{n}}}$ and NMR of four compounds from a culture of B. obtusa and their biological activities. We also report the 
results of the analysis of wood of grapevine infected in vitro by $B$. obtusa, where mellein was identified and $\delta$-resvertarol (trans-3,4',5-trihydroxystilbene) was oxidised in its dimer $\delta$-viniferin.

\section{Materials and methods}

Chemical analysis and characterisation

Fractionation and purification of extracts were performed on silica gel 60 (Brunschwig chemie N1, 32$63 \mathrm{~A}^{\circ}$ ) and Sephadex LH-20 (Pharmacia Fine Chemicals Inc., NJ, USA). The UV spectra were recorded on an Ultrospec $4000 \mathrm{UV} /$ visible spectrophotometer. IR spectra were measured on a Perkin Elmer FT-IR spectrometer, Paragon 1000 (Waltham, MA, USA). Negative ESI-MS were measured on a LCQ Finnigan (San José, CA, USA), and HRMS were recorded on a Bruker FTMS 4.7T, BIOAPEXII. The 1D and 2D NMR spectra were recorded on Bruker AMX-400 Spectrometer. Chemical shifts are given in $\delta$ from TMS; trans- $\delta$-resveratrol standard was obtained from Sigma-Aldrich (St Louis, MO, USA), $\delta$-viniferin was isolated in the laboratory by oxidation of resveratrol in a culture of Botrytis cinerea as described by Breuil et al. (1998) and Cichewicz et al. (2000).

Botryosphaeria obtusa strain and culture conditions

Strain F-99-2 of B. obtusa was isolated by Dr. Philippe Larignon in July 1999 from a Cabernet Sauvignon cultivar in St Julien de Beychevelle (France) and maintained on malt agar. Plugs of seven day-old potato dextrose agar (PDA) growth of $B$. obtusa were transferred in four flasks of 11 containing each $250 \mathrm{ml}$ of PDB, and kept under agitation at room temperature in the dark for 7 days. This medium was used for the inoculation of 151 of PDB medium, which was kept under agitation for 14 days in the dark. The medium was filtered on sheet cloth and extracted with an equal volume of ethyl acetate. After evaporation of the solvent to dryness we obtained $850 \mathrm{mg}$ of crude extract which was separated on a silica gel column $(70 \times 2 \mathrm{~mm}$ id $)$ with a mixture of hexane and an increasing volume of acetone. Fractions were monitored with thin layer chromatography (TLC) (Merck, Germany) and combined to six. The second, third and fifth fractions showed toxicity in a leaf disc assay. The second fraction $(425 \mathrm{mg}$ ) was successively applied to a Sephadex LH-20 column and eluted with methanol/chloroform $(1: 3, v / v)$ to yield $275 \mathrm{mg}$ of compound 1 . The third fraction (45 mg) was purified on HPLC with a MN Nucleosil column $7 \mu \mathrm{m}(250 \mathrm{~nm} \times 4.6 \mathrm{id})$ with and isocratic gradient of acetonitrile/water $(1: 3, v / v)$ during $20 \mathrm{~min}$, to yield $3.5 \mathrm{mg}$ and $5 \mathrm{mg}$ of compounds 2 and 3 respectively. The last fraction (12 $\mathrm{mg}$ ) was purified by thin layer chromatography (TLC) RP-18 $\mathrm{F}_{254}$ (Merck, Germany) with a mixture of methanol/water $(4: 6, v / v)$ to yield $7 \mathrm{mg}$ of 4 .

\section{Infection of grapevine wood}

Wood of grapevine (Gamay) collected at Agroscope Changin-Wädenswil, was dried and ground into powder $(1.2 \mathrm{Kg})$, which was divided into three parts of $400 \mathrm{~g}$, humidified with $150 \mathrm{ml}$ of water and placed in a plastic bag (Unicorn, TX, USA) and then sterilised twice in $24 \mathrm{~h}$. Two bags were infected by adding 30 PDA plugs of $B$. obtusa. The third was considered as a control. The bags were kept in the dark at $24^{\circ} \mathrm{C}$ for 40 days. Each bag was than extracted with 21 of methanol to yield $13 \mathrm{~g}$ to $15 \mathrm{~g}$ of crude extract. A sample of $5 \mathrm{mg} \mathrm{ml}^{-1}$ of acetonitrile/water, $(1: 1, v / v)$ was prepared, filtered and injected on LCMS for analysis. One hundred milligrams of the crude extract was fractionated on a Chromabond RP18 column (Macherey-Nagel GmbH, Düren, Germany) with a gradient of water/methanol, leading to three fractions. A solution of $5 \mathrm{mg} \mathrm{ml}^{-1}$ in methanol of each fraction was prepared and $25 \mu$ linjected for analysis by HPLC.

\section{LC/UV-DAD/ESI-MS ${ }^{\mathrm{n}}$}

Chromatographic analyses were carried out on a $\mathrm{MN}$ Nucleosil C-18 column $7 \mu \mathrm{m}$ (250 nm x 4.6 id). The mobile phase consisted of two solvents: water/acetic acid $(0.1 \%)(\mathrm{A})$ and acetonitrile (B). The linear gradient started with $20 \%$ of $\mathrm{B}$ and increased to $100 \%$ within $27 \mathrm{~min}$ and returned to the initial condition at $35 \mathrm{~min}$. The flow rate was $1 \mathrm{ml} \mathrm{min} \mathrm{m}^{-1}$ and the injection volume was $25 \mu$ l. Spectral data from all peaks were accumulated in the range between $240 \mathrm{~nm}$ and $400 \mathrm{~nm}$, and chromatograms were recorded at $280 \mathrm{~nm}$ and $307 \mathrm{~nm}$ for stilbenes and 


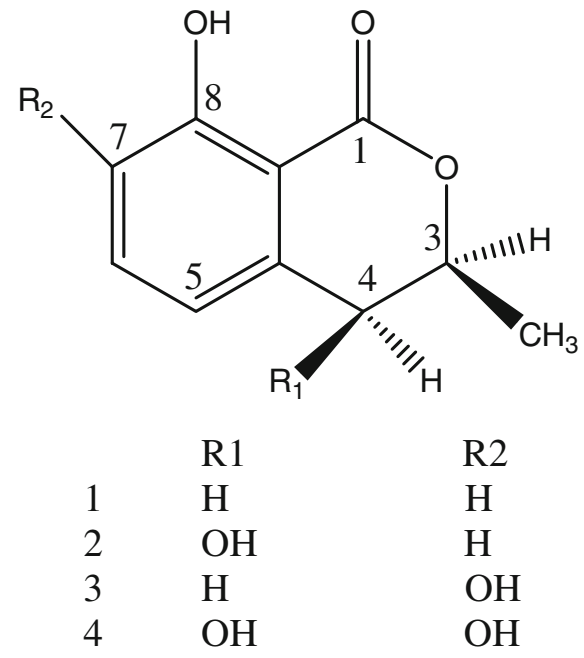

Fig. 1 Structure of compounds 1-4

derivatives and $254 \mathrm{~nm}$ and $360 \mathrm{~nm}$ for dihydroisocoumarin. The LC/UV-DAD/ESI-MS ${ }^{\mathrm{n}}$ analysis was carried out on an Agilent HPLC 1100 equipped with a diode array detector and coupled to an Agilent LC/ MSD trap mass detector with ESI sources in negative or positive ionisation mode. Mass condition analysis was optimised by direct injection of a solution of resveratrol or mellein at a concentration of $0.1 \mathrm{mg} \mathrm{ml}^{-1}$.

\section{Leaf disc assay}

The toxicity of isolated compounds was evaluated by means of a leaf disc assay. Discs (9 mm diam) of Chasselas, were placed in a 24 -well plate containing water with different concentrations of the toxin and maintained at $25^{\circ} \mathrm{C}$. After $12 \mathrm{~h}$, the necrosis induced on the leaves was measured.
Antifungal-activity assay

Trans- $\delta$-resveratrol, $\varepsilon$-viniferin and $\delta$-viniferin were tested for antifungal activity against $B$. obtusa by using the paper-disc method. Two $6 \mathrm{~mm}$ discs of sterile paper were soaked in each of the compounds $(0.25 \mathrm{mg}$ in $50 \mu \mathrm{l}$ of acetone). The air-dried discs were placed on a PDA plate. Each plate was then inoculated with an agar block ( $6 \mathrm{~mm}$ diam) containing mycelial mats of the fungus in the centre of the plate. The paper discs were $2.2 \mathrm{~cm}$ from the phytopathogen.

\section{Results and discussion}

The ethyl acetate extract of B. obtusa $(850 \mathrm{mg})$ of 151 culture filtrate, was fractionated and purified by chromatography to yield four pure compounds. (Fig. 1) Compound 1 crystallised from the chromatographic fraction obtained by a mixture of hexane/acetone $(9: 1, v / v)$ at a yield corresponding to $18 \mathrm{mg}^{-1}$ of culture filtrate. The MS spectrum in negative ion mode shows a peak at m/z $177[\mathrm{M}-\mathrm{H}]^{-}$. Fragmentation showed dominant signals due to the loss of $\mathrm{H}_{2} \mathrm{O}$ and $\mathrm{MeCHO}$ by the retro-Diels-Alder reaction characteristic of mellein and its derivatives. These results together with ${ }^{13} \mathrm{C}$ NMR spectroscopic data suggested the molecular formula of $\mathrm{C}_{10} \mathrm{H}_{10} \mathrm{O}_{3}$. Furthermore, the IR, UV, ${ }^{1} \mathrm{H}$ NMR MS and CD data were identical to data reported for mellein (Venkatasubbaiah and Chilton 1990). Mellein has been reported from several other fungi and both enantiomers have been isolated previously. $S-(+)$ has been isolated from Apiospora camptospora (Devys et al. 1974), Aspergillus ochraceus (Moore et al. 1972), Cercospora taiwanensis (Camarda et al. 1976), Fusarium larvarum (Grove and Pople

Table $1{ }^{1} \mathrm{H}$ NMR data of compounds $1-4\left(1-3\right.$ in $\mathrm{CDCl}_{3}$ and 4 in acetone- $\left.\mathrm{d}_{6}\right)$

\begin{tabular}{lllll}
\hline & $1(\delta, \mathrm{m}, \mathrm{J})$ & $2(\delta, \mathrm{m}, \mathrm{J})$ & $3(\delta, \mathrm{m}, \mathrm{J})$ & $4(\delta, \mathrm{m}, \mathrm{J})$ \\
\hline 3 & $4.72, \mathrm{~m}$ & $4.73, \mathrm{~m}$ & $4.76, \mathrm{~m}$ & $4.77, \mathrm{~m}$ \\
4 & $2.92, \mathrm{t}$ & $4.60, \mathrm{~d}, 2.0$ & $2.90, \mathrm{t}, 7.52$ & $4.58, \mathrm{brs}$ \\
5 & $6.88, \mathrm{dd}, 0.3,8.4$ & $6.96, \mathrm{dd}, 1.0,8.5$ & $6.64, \mathrm{~d}, 8.0$ & $7.88, \mathrm{~d}, 8.9$ \\
6 & $7.40, \mathrm{dd}, 7.4,8.4$ & $7.55, \mathrm{dd}, 8.5,7.3$ & $7.10, \mathrm{~d}, 8.0$ & \\
7 & $6.70, \mathrm{dd}, 0.8,7.4$ & $6.94, \mathrm{dd}, 1.0,7.3$ & \\
10 & $1.53, \mathrm{~d}, 6.1$ & $1.61, \mathrm{~d}, 16.6$ & $1.55, \mathrm{~d}, 6.3$ & \\
$7-\mathrm{OH}$ & $11.03, \mathrm{~s}$ & & & \\
$8-\mathrm{OH}$ & & $11.03, \mathrm{~s}$ & $11.08, \mathrm{~s}$ & $1.53, \mathrm{~d}, 6.5$ \\
\hline
\end{tabular}


Table $2{ }^{13} \mathrm{C}$ NMR data of compounds $1-4\left(1-3\right.$ in $\mathrm{CDCl}_{3}$ and 4 in acetone- $\left.\mathrm{d}_{6}\right)$

\begin{tabular}{lrrrr}
\hline & 1 & 2 & 3 & 4 \\
\hline 1 & 170.4 & 169.6 & 170.6 & \\
2 & & & 77.5 & 170.3 \\
3 & 76.5 & 78.1 & 34.4 & 66.5 \\
4 & 34.9 & 67.6 & 118.0 & 118.9 \\
5 & 116.6 & 118.7 & 120.9 & 121.5 \\
6 & 136.7 & 137.2 & 144.2 & 146.2 \\
7 & 118.3 & 119.0 & 149.3 & 149.9 \\
8 & 162.5 & 162.5 & 130.1 & 132.9 \\
$4 \mathrm{a}$ & 139.8 & 140.9 & 108.6 & 107.9 \\
$8 \mathrm{a}$ & 108.6 & 107.2 & 21.1 & 16.2 \\
10 & 21.1 & 16.4 & & \\
\hline
\end{tabular}

1979) and Sphaeropsis sapinea (Cabras et al. 2006). R-(-)-mellein has been reported from B. obtusa (Venkatasubbaiah and Chilton 1990; Venkatasubbaiah et al. 1991) and more recently from Botryosphaeria mamane (Pongcharoen et al. 2007). Due to the CD data, the isolated metabolite was identified as $R-(-)-$ mellein.

Compound 2 was isolated as colourless oil at a yield of $0.25 \mathrm{mg} \mathrm{l}^{-1}$ of culture. Its mass spectrum, in negative ionisation mode, exhibited a pseudo molecular ion at $\mathrm{m} / \mathrm{z} 193$, indicating one more oxygen atom than mellein and suggesting the molecular formula $\mathrm{C}_{10} \mathrm{H}_{10} \mathrm{O}_{4}$. MS ${ }^{2}$ spectra showed a similar fragmentation pattern to that of mellein. The infra red spectra of compound 2 was similar to that of compound 1 . On the ${ }^{1} \mathrm{H}$ NMR spectrum seven protons were observed (Table 1). Compound 2 was identified as $(3 R, 4 R)$-cis4-hydroxymellein according to data reported by Cole et al. (1971) and Devys et al. (1980).

Compound 3 was isolated as a colourless oil at a yield of $0.33 \mathrm{mg} \mathrm{l}^{-1}$ of culture. It had the same pseudo-molecular ion as compound 2. On the ${ }^{1} \mathrm{H}$ NMR spectrum only two AB protons were observed in the aromatic portion, appearing as a doublet at $\delta$ 6.64 and 7.10 with the same coupling constant of $8 \mathrm{~Hz}$. Compound 3 was identified as (3R)-7-hydroxymellein (Devys et al. 1980).

Compound 4 was isolated as a yellow oil at yield of $0.5 \mathrm{mg}^{-1}$. The absorption maxima were observed at $260 \mathrm{~nm}$ and $335 \mathrm{~nm}$ on the UV spectra. The mass spectrum in ESI negative ionisation mode showed a pseudo molecular ion at $\mathrm{m} / \mathrm{z} 209[\mathrm{M}-\mathrm{H}]^{-}$. This mass was confirmed in positive ionisation mode with high resolution mass spectrometry m/z $233.04229[\mathrm{M}+\mathrm{Na}]^{+}$. The fragmentation showed signals due to the loss of
$\mathrm{H}_{2} \mathrm{O}(\mathrm{m} / \mathrm{z}$ 191) and $\mathrm{MeCHO}(\mathrm{m} / \mathrm{z}$ 165) by a retro-DielsAlder reaction characteristic of mellein and derivatives (Venkatasubbaiah and Chilton 1990). These results together with ${ }^{13} \mathrm{C}$ NMR spectroscopic data suggested the molecular formula of $\mathrm{C}_{10} \mathrm{H}_{10} \mathrm{O}_{5}$. Furthermore, the IR spectrum displayed characteristic absorptions for hydroxyl groups $\left(3,200 \mathrm{~cm}^{-1}\right)$, lactone function $\left(1,674 \mathrm{~cm}^{-1}\right)$ and aromatic rings $\left(1,607 \mathrm{~cm}^{-1}\right)$. On the ${ }^{1} \mathrm{H}$ NMR spectra recorded in acetone there were seven protons (Table 1) including two $\mathrm{AB}$ aromatic protons at $\delta 6.88(\mathrm{~d}, J 8.9 \mathrm{~Hz}, \mathrm{H}-5)$ and 7.13 (d, $J 8.9 \mathrm{~Hz}, \mathrm{H}-6)$ and one methyl signal at $\delta 1.53(\mathrm{~d}, J 6.6 \mathrm{~Hz})$. Two methine protons were observed at $\delta 4.58(\mathrm{~d}, J 3.6 \mathrm{~Hz}$, $\mathrm{H}-4)$ and 4.77 (H-3) as a quadruplet, and finally two hydroxyl protons $\left(\mathrm{D}_{2} \mathrm{O}\right.$ exchangeable) appeared at $\delta$ 8.20 (OH-C-7) and 11.13 (OH-C-8). In the ${ }^{1} \mathrm{H}-{ }^{1} \mathrm{H}$ COSY spectrum, H-3 showed correlation with $\mathrm{H}-4$ and the proton of the methyl group. HSQC spectrum showed a correlation from the singlet methine protons

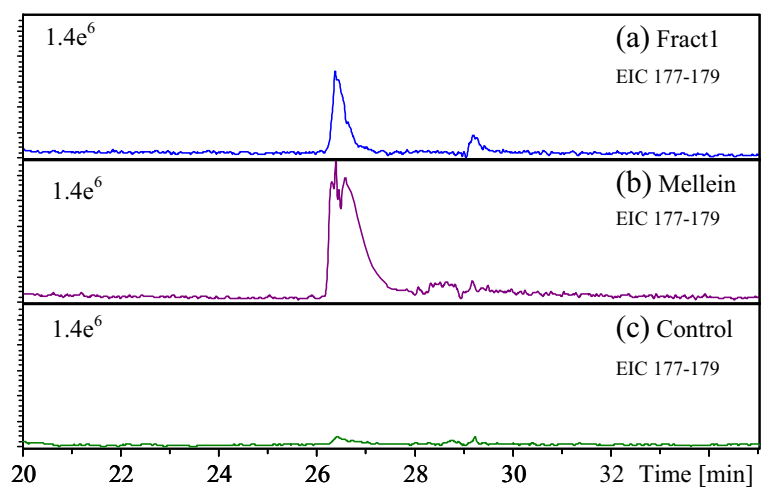

Fig. 2 MS chromatogram : a fraction 1 eluted with methanol from wood infected with $B$. obtusa, b mellein and c control (uninfected wood) 
at $\delta 6.88$ and 7.13 to the aromatic carbon atom at $\delta$ 118.9 and 121.5 respectively. In the HMBC spectral data (Fig. 1), ${ }^{1} \mathrm{H}-{ }^{13} \mathrm{C}$ long range correlations were observed between the methine protons at $\delta 6.88$ (H-5) and the carbons C-1 (170.3), C-8a (107.9), C-4a (132.9), C-7 (146.2), C-6 (121.5) and C-4 (66.5). The second aromatic methine proton at $\delta 7.13(\mathrm{H}-6)$ correlated with carbons at C-8 (149.9), C-7 (146.2), C-8a (107.9) and C-5 (118.9). On the pyrone cycle the methine at $\delta 4.63$ correlated with carbons at C-8a (107.9), C-5 (118.9), C-4a (132.9) and C-3 (79.7), the methyl proton at $\delta 1.53$ correlated with carbons at C-3 (79.7) and C-4 (66.5). Thus, the complete structure of 4 was determined as (3R,4R)-cis-4,7-dihydroxymellein (Tables 1 and 2).

A bioassay against grape leaf was performed by submerging discs of the grapevine variety Gamay in a solution containing the toxin at different concentrations for $12 \mathrm{~h}$. The bioassay showed that compound 4 was the most active by inducing a full leaf necrosis with minimum inhibitory concentrations (MIC) of $2 \mu \mathrm{g} \mathrm{ml}^{-1}$, although compounds 1,2 and 3 possessed a similar level of toxicity with MIC of $3 \mu \mathrm{g} \mathrm{ml}^{-1}$ (data not shown).

In order to verify if the fungus was able to synthesise the same toxins on natural medium, wood powder of grapevine var. Gamay was infected with agar plugs of $B$. obtusa and kept in sterile plastic bags at room temperature in the dark for 40 days. HPLCDAD-MS analysis of the methanolic extract and the fractions showed the presence of mellein in fraction 1 (100\% methanol) Fig. 2.

The presence of mellein is a good molecular marker for the presence of fungi in the diseased plant. Venkatasubbaiah et al. (1991) found mellein and 4 hydroxymellein in infected apple fruit. Since mellein has been reported from several fungi, it cannot be considered a marker for B. obtuse; however, mellein and dihydroxycoumarin have never been reported from Phaeoacremonium aleophilum, Phaeomoniella chlamydospora or Fomitiporia mediterranea, the main pathogens in esca disease (Tabacchi et al. 2000; Evidente et al. 2000; and Abou-Mansour et al. 2004). Therefore, mellein would make a good molecular marker for early differentiation between esca and BDA disease.

Furthermore, in the non-infected wood, trans- $\delta$ resveratrol was one of the major compounds observed in the methanolic extract at $\lambda 307 \mathrm{~nm}$. However, during analysis of the extracts of the infected wood, $\delta$-resveratrol was not detectable by UV or by mass spectrometry. Instead, a new compound identified as $\delta$-viniferin appeared. $\delta$ - viniferin has been reported as a molecule produced in vitro by the oxidative dimerisation of $\delta$-resveratrol by plant peroxidases or fungal laccases (Pezet et al. 1991; Breuil et al. 1998). The strain of B. obtusa used in our study was able to produce laccase enzyme to stain a full PDA Petri dish, incorporating the laccase substrate ABTS, blue green within $12 \mathrm{~h}$ (data not shown).

However, $\delta$-viniferin has previously been shown to exhibit in vitro antifungal activity against Botrytis cinerea (Langcake and Pryce 1976). However, in our in vitro antifungal assay based on the disc diffusion method, neither $\delta$-resveratrol, $\varepsilon$-viniferin nor $\delta$ viniferin exhibited any activity against $B$. obtusa, at a concentration of $250 \mu \mathrm{g}$.

In conclusion, bioassay-guided purification of ethyl acetate extract of B. obtusa yielded four toxic compounds, among them 7-hydroxymellein isolated for the first time from this fungus, and 4,7-dihydroxymellein also described for the first time. The grapevine wood infected in vitro with B. obtusa showed the presence of mellein and the absence of the dihydroxycoumarin moiety in general, and the complete oxidation of resveratrol into its dihydromer $\delta$-viniferin. Even though mellein is an non-specific toxin, it could provide a molecular marker for the early differentiation of BDA from esca disease in grapevine. However, the field system still needs investigation of the isolated dihydroxymellein in naturally infected grapevine wood.

Acknowledgments This project was funded by the National Centre of Competence in Research (NCCR) Plant Survival, a research programme of the Swiss Science Foundation, and supported by European Cooperation in the field of Scientific and Technical Research (COST) Action 858 and by a grant from the State Secretariat for Education and Research (Switzerland).

\section{References}

Abou-Mansour, E., Couché, E., \& Tabacchi, R. (2004). Do fungal naphthalenones have a role in the development of esca symptoms? Phytopathologia Mediterranea, 43, 75-82.

Breuil, A. C., Adrian, M., Pirio, N., Meunier, P., Bessis, R., \& Jeandet, P. (1998). Metabolism of stilbene phytoalexins by Botrytis cinerea: 1. Characterization of a resveratrol dehydrodimer. Tetrahedron Letters, 39, 537-540. doi:10.1016/S0040-4039(97)10622-0.

Cabras, A., Mannoni, M., Serra, S., Andolfi, A., Fiore, M., \& Evidente, A. (2006). Occurrence, isolation and biological activity of phytotoxic metabolites produced in vitro by 
Sphaeropsis sapinea, pathogenic fungus of Pinus radiata. European Journal of Plant Pathology, 115, 187-193. doi:10.1007/s10658-006-9006-7.

Camarda, L., Merlini, L., \& Nasini, G. (1976). Metabolites of Cercospora. Taiwapyrone, an $\alpha$-pyrone of unusual structure from Cercospora taiwanensis. Phytochemistry, 15, 537-539. doi:10.1016/S0031-9422(00)88966-9.

Cichewicz, R. H., Kouzi, S., \& Hamann, M. (2000). Dimerization of resveratrol by the grapevine pathogen Botrytis cinerea. Journal of Natural Products, 63, 29-33. doi:10.1021/np990266n.

Cole, R. J., Moore, N. D., Kiksey, J. W., \& Diener, J. (1971). 4Hydroxymellein. A New metabolite of Aspergillus ochraceus. Journal of Agricultural and Food Chemistry, 19, 909-911. doi:10.1021/jf60177a003.

Cristinzio, G. (1978). Gravi attachi di Botryosphaeria obtusa su vite in provincia di Isernia. Informatore Fitopatologico, $28,21-23$.

Devys, M., Bousquet, J. F., Skajennikoff, M., \& Barbier, M. (1974). Lochracine (meiléine), phytotoxine isolée du milieu de culture de Septoria nodorum Berk. Journal of Phytopathology, 81, 92-94. doi:10.1111/j.1439-0434.1974.tb02781.x.

Devys, M., Bousquet, J. F., Kollmann, A., \& Barbier, M. (1980). Dihydroisocoumarines et acide mycophenolique $\mathrm{du}$ milieu de culture du champignon phytopathogene Septoria nodorum. Phytochemistry, 19, 2221-2222. doi:10.1016/S0031-9422(00)82234-7.

Evidente, A., Sparapano, L., Andolfi, A., \& Giovanni, B. (2000). Two naphthalenone pentaketides from liquid cultures of Phaeoacremonium aleophilum, a fungus associated with esca of grapevine. Phytopathologia Mediterranea, 44, 161-168.

Grove, J. F., \& Pople, M. (1979). Metabolic products of Fusarium larvarum Fuckel. The fusarentins and the absolute configuration of monocerin. Journal of the Chemical Society, Perkin Transactions 1: Organic and Bio-Organic Chemistry, 2048-2051. doi:10.1039/p19790002048.

Langcake, H., \& Pryce, R. J. (1976). The production of resveratrol and the viniferins by Vitis vinifera and other members of Vitaceae as a response to infection or injury. Physiological Plant Pathology, 9, 77-86. doi:10.1016/ 0048-4059(76)90077-1.

Larignon, P., \& Dubos, B. (2001). Le Black bead arm. Maladie nouvelle à ne pas confondre avec l'esca Phytoma, 538, 26-29.

Larignon, P., Fulchic, R., Cere, L., \& Dubos, B. (2001). Observation on black dead Arm in French vineyards. Phytopathologia Mediterranea, 40, S336-S342.

Lehoczky, J. (1974). Black dead arm disease of grapevine caused by Botryosphaeria stevensii infection. Acta Phytopathologica Academiae Scientiarum Hungaricae, 9, 319-327.

Moore, J. H., Davis, N. D., \& Diener, U. L. (1972). Mellein and 4-hydroxymellein production by Aspergillus ochraceus Wilhelm. Applied Microbiology, 23, 1067-1072.

Pezet, R., Pont, V., \& Hoang-Van, K. (1991). Evidence for oxidative detoxification of pterostilbene and resveratrol by a laccase-like stilbene oxidase produced by Botrytis cinerea. Physiological and Molecular Plant Pathology, 39, 441-450. doi:10.1016/0885-5765(91)90010-F.

Pongcharoen, W., Rukachaisirikul, V., Phongpaichit, S., \& Sakayaroj, J. A. (2007). New dihydrobenzofuran derivative from the endophytic fungus Botryosphaeria mamane PSU-M76. Chemical \& Pharmaceutical Bulletin, 55, 1404-1405. doi:10.1248/cpb.55.1404.

Rovesti, L., \& Montermini, A. (1987). Un deperimento della vite causato da Sphaeropsis malorum diffuso in provincia di Reggio Emilia. Informatore Fitopatologico, 37, 5961.

Tabacchi, R., Fkyerat, A., Poliart, C., \& Dubin, D. M. (2000). Phytotoxins from fungi of esca of grapevine. Phytopathologia Mediterranea, 39, 156-161.

Venkatasubbaiah, P., \& Chilton, W. S. (1990). Phytotoxins of Botryosphaeria obtusa. Journal of Natural Products, 53, 1628-1630. doi:10.1021/np50072a044.

Venkatasubbaiah, P., Sutton, T. B., \& Chilton, W. S. (1991). Effect of Phytotoxins Produced by Botryosphaeria obtusa, the Cause of Black Rot of Apple Fruit and Frogeye Leaf Spot. Phytopathology, 81, 243-247. doi:10.1094/Phyto-81-243. 